\title{
Programação de computadores como uma alternativa ao modelo metodológico padrão da apropriação da informática em processos educativos
}

\section{Computer programming as an alternative to the standard methodological model of appropriation of information technology in educational processes}

\author{
Marco Antonio Sandini Trentin ${ }^{*}$ \\ Ricardo Shitsuka* \\ Adriano Canabarro Teixeira***
}

\section{Resumo}

Devido ao crescente uso dos mais diversos aparatos tecnológicos na sociedade atual e às possibilidades que estes podem trazer para a educação, este artigo traz uma reflexão acerca dos desdobramentos da informática no contexto da educação brasileira e, mais especificamente, sobre como criar condições para que o conhecimento possa ser construído pelas crianças por meio da programação de computadores. Esta pesquisa apresenta um referencial teórico sobre o construcionismo, que busca possibilitar ao estudante desenvolver meios de aprendizagem que valorizem a sua construção mental, libertando seu pensamento criativo apoiado em suas próprias percepções de mundo, que, em última análise, pode servir a qualquer situação de aprendizagem futura. Por fim, apresenta alguns resultados de desdobramentos do ato de programar por alunos da educação básica.

Palavras-chave: Ensino de computação. Informática em Educação. Tecnologia educacional.

\section{Abstract}

Due to the increasing use of the most diverse technological apparatuses in the current society and the possibilities that these can contribute to the education, this article brings a reflection on the unfolding of informatics in the context of the Brazilian education and, more specifically, on how to create conditions for knowledge be built by children through computer programming. This research made use of the theoretical framework of Construccionism, which seeks to enable students to develop learning resources that enhance their mental construction, releasing their creative thinking based on their own perceptions of the world that can ultimately serve any future learning situation. Finally, it presents some results of the unfolding act of programming by students of Basic Education.

Keywords: Computer education. Informatics in Education. Educational technology.

\author{
Recebido em 24/09/2018 - Aprovado em 10/01/2010 \\ http://dx.doi.org/10.5335/rep.v26i2.9413
}

Doutor em Informática na Educação pela Universidade Federal do Rio Grande do Sul. Professor do Curso de Ciência da Computação e do Programa de Pós-Graduação em Ensino de Ciências e Matemática da Universidade de Passo Fundo, Brasil. E-mail: trentin@upf.br

** Doutor em Ensino de Ciências pela Universidade Cruzeiro do Sul. Professor dos cursos de Engenharia na Universidade Federal de Itajubá, campus Itabira, e do Programa de Pós-Graduação em Educação em Ciências da Universidade Federal de Itajubá, Brasil. E-mail: ricardoshitsuka@unifei.edu.br

*** Doutor em Informática na Educação pela Universidade Federal do Rio Grande do Sul. Professor do Curso de Ciência da Computação, do Programa de Pós-Graduação em Educação e do Programa de Pós-Graduação em Ensino de Ciências e Matemática da Universidade de Passo Fundo, Brasil. E-mail: teixeira@upf.br 


\section{Introdução}

É uma tarefa árdua argumentar consistente e contrariamente ao fato de que os dispositivos tecnológicos presentes no cotidiano humano e nos mais diversos setores em que atuamos constituem artefatos fundamentais para a dinâmica do mundo contemporâneo. O teórico André Lemos (2002), ao tratar do tema da cibercultura, deixa esta percepção bem clara ao apontar que essas tecnologias, mais do que influenciar, determinam a forma como vivemos.

De fato, a utilização de computadores em áreas como a Medicina e a Engenharia, por exemplo, proporcionou avanços fundamentais e inimagináveis nos resultados de suas ações sobre o mundo. Tal contexto advém do fato de que os poderes de processamento, armazenamento e transmissão de informações desses aparatos possibilitam um processo analítico dos dados, baseado na manipulação de uma grande massa de informações, na comunicação instantânea entre os profissionais e na imediata disponibilização e divulgação dos conhecimentos gerados no processo.

$\mathrm{Na}$ educação, os aparatos tecnológicos, que não são poucos em variedade, a perspectiva não foi diferente. Nos mais de 20 anos de informática educativa, apresentados neste texto a partir do advento do Programa Nacional de Informática na Educação (Proinfo), uma das iniciativas pioneiras no contexto nacional é possível identificar claramente três momentos. O primeiro, quando comumente os computadores eram vistos como a solução para as mazelas de nossa educação, tinha por objetivo informatizar as escolas públicas brasileiras por meio da disponibilização de laboratórios de informática. Junto com esse processo, ganhou corpo um movimento em torno da implementação de softwares educativos. Tão pouco mencionados ultimamente, tiveram seu ápice de desenvolvimento e de pesquisas por volta dos anos 2000, quando era unânime a ideia de que se precisava desenvolver aplicações educacionais a serem utilizadas nos laboratórios. O terceiro momento, que teve seu início por volta de 2007, coincide com o início do processo de conexão das escolas, dando destaque à demanda de criação de ambientes virtuais de aprendizagem (AVAs), ou seja, sites na Web, em que se pudesse desenvolver - e controlar - atividades de ensino e aprendizagem. Neste período, foram desenvolvidas várias plataformas e outras que já existiam, como é o caso do Teleduc e do Moodle, ganharam força.

É claro que não se trata de um percurso no qual estas diferentes etapas têm fronteiras claras, e, no Brasil, existe ainda uma parcela de escolas que não possuem sequer energia elétrica, portanto, ainda precisam passar pela primeira situação. Contudo, a esmagadora maioria precisa avançar significativamente na qualificação 
da conexão existente. Portanto, ao tempo em que não se pode ignorar o fato de que se tem avançado significativa e concorrentemente nos três sentidos, ainda se tem um longo e urgente caminho a ser trilhado no âmbito da conexão à internet, que, desde 2011, é apontado pelo Organização das Nações Unidas como um direito do cidadão.

De qualquer modo, o objetivo deste breve resgate do histórico do movimento de informatização da educação não consiste no aprofundamento desta análise, mas sim na reflexão acerca dos desdobramentos dessas três etapas sobre o contexto da educação brasileira. $\mathrm{O}$ fato é que, nos últimos três anos, um grande número de escolas no Brasil vivenciou um processo em que, além do laboratório de informática do Proinfo, foram recebidos laptops educacionais, tablets e lousas digitais. Em uma análise ingênua e míope sobre esse contexto, seria possível intuir que a presença desses dispositivos, de alguma forma, leva inevitavelmente à qualificação dos processos educativos, uma vez que, em sua essência, são democráticos e abrem possibilidades de acesso a informações e bens culturais até então não disponíveis à maioria da população, permitindo o estabelecimento de processos comunicacionais entre indivíduos independente de barreiras espaço-temporais.

Também não é difícil argumentar em torno do fato de que tais tecnologias, da forma como têm sido apropriadas até então, não têm trazido ganhos significativos à educação, cujo papel é, em uma primeira análise, formar o cidadão para o mundo de hoje. Prova disso é o desempenho brasileiro registrado nos mais diversos relatórios construídos por diferentes organizações acerca da qualidade da educação ou do desempenho de alunos ao redor do mundo. Nesses estudos, o Brasil tem aparecido recorrentemente nas últimas posições. A Organização para a Cooperação e Desenvolvimento Econômico (OCDE), ao avaliar 36 países, coloca o Brasil na penúltima posição (ORGANISATION FOR ECONOMIC CO-OPERATION AND DEVELOPMENT, 2014). Em um estudo ainda mais abrangente, também coordenado pela OCDE, a situação não é diferente, quando, em 2012, foram avaliados 65 países por meio do Programa Internacional de Avaliação de Estudantes (Pisa) ${ }^{1}$.

Não se trata de encarar a informática como a solução dos problemas e das demandas da educação brasileira, mas sim de uma argumentação rápida acerca da evidência de que as contribuições do potencial dessas tecnologias na educação não chegam nem perto do que aconteceu em outras áreas. A percepção é a de que já se teve tempo suficiente para que se pudesse avaliar o potencial das tecnologias da forma como estão inseridas no contexto escolar, no âmbito da educação formal e diária. Percepções positivas acerca desta simbiose advêm, invariavelmente, das interseções existentes entre a escola do mundo real e a pesquisa do mundo acadê- 
mico, que prioriza uma visão da informática educativa como espaço interdisciplinar, como uma oportunidade de desenvolver processos educativos em que os indivíduos então dispersos pelos mais variados lugares do mundo, do desenvolvimento de objetos digitais de aprendizagem com os mais diferentes formatos e fins, com a utilização de AVAs, entre tantas outras possibilidades.

Entretanto, o que se verifica no ambiente escolar é que, além de não ter trazido ganhos significativos, ao menos os resultados de muitas avaliações que vão neste sentido, as tecnologias digitais perdem força inclusive enquanto elementos atrativos e motivadores - por vezes punitivo - para os estudantes, inclusive aqueles que só têm acesso direto aos computadores na escola. É possível afirmar que é cada vez mais difícil a proposta de atividades utilizando os computadores que de fato envolvam e desafiem os estudantes, uma vez que os ambientes e os softwares utilizados fora da escola são mais desafiadores, possuem mais possibilidades de imersão e os colocam em uma situação de protagonismo. Essas três características já foram apontadas por Wim Veen e Ben Vrakking (2009) como as responsáveis pelo fascínio que os jovens apresentam por jogos de computadores em detrimento de outras atividades, como, por exemplo, ler um livro.

A partir desse contexto, desde 2013, o Grupo de Estudo e Pesquisa em Inclusão Digital (Gepid) e os pesquisadores do Programa de Pós-Graduação em Educação da Universidade de Passo Fundo (UPF) têm desenvolvido pesquisas e experiências em torno de uma alternativa à utilização de computadores na educação. O grupo acredita que, dado o contexto de abundância de possibilidades que esta situação de informatização oferece, de acesso e geração de informações, da provisoriedade do conhecimento científico e da impossibilidade de a escola dar conta de formar um cidadão para um mundo de futuros imprevisíveis, é fundamental explorar possibilidades que trabalhem não na perspectiva de interdisciplinaridade com a utilização de soluções tecnológicas, mas que criem um ambiente favorável ao desenvolvimento da criatividade, ao aumento da capacidade de resolução de problemas e ao desenvolvimento do raciocínio lógico-matemático. Tal opção leva a crer que, em última instância, é possível identificar desdobramentos sobre o desempenho dos estudantes nas mais diversas áreas.

Dentre essas pesquisas, destacam-se as que se desenvolvem em torno da programação de computadores por estudantes do ensino fundamental na rede pública do município de Passo Fundo, denominada Escola de Hackers, e as atividades propostas a grupos de alunos da educação infantil, de 5 e 6 anos de idade, no projeto Mutirão pela Inclusão Digital. Posto isso, o objetivo deste artigo é apresentar 
parcialmente as bases teóricas que sustentam a exploração da programação de computadores como elemento potencialmente qualificador de processos educativos formais.

\section{As bases construcionistas da programação de computadores}

Um dos pioneiros na história da informática na educação foi Seymour Papert, nascido no ano de 1928 e criado em Pretória, na África do Sul, internacionalmente reconhecido como um dos precursores e defensores da ideia de que as tecnologias podem qualificar os processos de aprendizagem, é matemático e considerado o pai do campo da inteligência artificial. Papert engajou-se em projetos na área da Matemática e trabalhou com Piaget na Universidade de Genova, de 1958 a 1963, quando sua colaboração principal foi acompanhar o uso da matemática como espaço de compreensão do raciocínio em crianças.

Papert criou o conceito de "construcionismo", que é uma reconstrução teórica a partir do construtivismo piagetiano. O matemático concorda com Piaget, quando afirma que a criança é um ser pensante e construtor de suas próprias estruturas cognitivas, mesmo sem ser ensinado. Inquietando-se com o número reduzido de pesquisas nessa área na época, levantou a seguinte questão: como criar condições para que mais conhecimento possa ser construído pelas crianças? Para o autor, a atitude construcionista implica ensinar de tal forma a produzir o máximo de aprendizagem, com o mínimo de ensino, ou seja, potencializar o envolvimento do estudante no que deseja aprender em contraposição ao falar/ditar do professor. O construcionismo busca possibilitar ao estudante desenvolver meios de aprendizagem fortes, que valorizem a sua construção mental, libertando seu pensamento criativo apoiado em suas próprias percepções de mundo, que, em última análise, pode servir a qualquer situação de aprendizagem futura.

Papert conseguiu demonstrar os princípios psicológicos e pedagógicos do aprender fazendo e da aprendizagem significativa e reflexiva, além da integração no contexto da afetividade e da interação. $O$ construcionismo, ainda, foi de fundamental importância para direcionar ações de mediação do professor para com o aluno, quando ambos interagem em processos que envolvem a construção do pensamento, demanda clara de processos envolvendo a programação de computadores. Sem dúvida, essa teoria está fundamentada no construtivismo piagetiano, na teoria de inteligências múltiplas de Gardner e na pedagogia social de Paulo Freire. Segundo Papert (2007, p. 23): 
Os materiais devem favorecer ao aluno a aprender-sobre-o-pensar é a ideia de "hands-on" e "head-in". Isto significa que o aluno aprende fazendo (colocando a mão na massa) e construindo algo que lhe seja significativo, de modo que possa envolver-se afetiva e cognitivamente com aquilo que está sendo produzido.

A possibilidade de programar um computador representou para Piaget uma poderosa forma de sistematização do pensamento, uma vez que suas linguagens de programação exigem pensamento procedural, possibilitando ao professor e ao estudante reconhecer os mecanismos que estão sendo utilizados para resolver determinado problema. É possível apontar para o fato de que o ser humano, quando passa a programar, criar seus próprios algoritmos, deixa de ser somente usuário do computador e assume o papel de protagonista, desafiado a resolver, da forma mais eficiente e criativa possível, determinados problemas e imerso em um mundo de possibilidades diretamente proporcional ao seu desenvolvimento cognitivo.

É importante salientar que Papert, já em $1971,{ }^{2}$ protagonizava a programação de computadores como uma ferramenta poderosa para a educação, e, agora, passados mais de 45 anos, o mundo começa de fato a explorar esta possibilidade. A fim de sustentar estas ideias iniciais, torna-se prudente refletir acerca dos elementos envolvidos no ato de programar, algumas alternativas de ambientes de programação e as habilidades e capacidades que desenvolvem.

\section{0 que está envolvido no ato de programar}

A programação proporciona ao aprendiz um ambiente desafiador que o estimula a pensar. Isso pressupõe um processo de aprendizagem ativa, em que a construção do conhecimento se dá a partir das ações físicas ou mentais do aluno. Programar envolve uma série de capacidades, dentre as quais, destacam-se: criatividade, capacidade de resolução de problemas, trabalho em grupo e raciocínio lógico.

A criatividade pode ser compreendida como um modo de utilizar e reutilizar a informação, mas também pode ser uma atitude. Sobre a criatividade, Vygotsky (2007, p. 15) assim se posiciona: "Entre as questões mais importantes da psicologia infantil e da pedagogia, encontra-se a da capacidade criadora das crianças, a da promoção desta capacidade e a da sua importância no desenvolvimento geral e maturação da criança”.

Nessa perspectiva, o pensamento criativo apresenta duas características principais: a revelação da autonomia sobre o que fazer e como fazer e a orientação para criações de novas ideias, partindo daquelas já existentes. Uma das capacidades 
usadas quando se está programando, fundamental para que haja a interação com computador - objeto e pessoa -, é o uso da imaginação, ou seja, da capacidade criadora.

Além da criatividade, a capacidade de resolução de problemas é uma competência matemática que leva a desenvolver inúmeras outras competências. Ponte et al. (2007) consideram que a resolução de problemas pode ser uma importante contribuição na formação integral do indivíduo. Pólya (2003) define a resolução de problemas como uma arte que todos podem aprender, na qual o objetivo é desenvolver a capacidade de pensar. Para o autor, a resolução de problemas inclui quatro etapas: compreensão do problema, elaboração de um plano, execução do plano e verificação dos resultados.

Além do desenvolvimento da criatividade e da habilidade na resolução de problemas, o trabalho em grupo também se faz importante para a aprendizagem eficiente por intermédio de programação. A necessidade de pensar soluções para um determinado problema e, posteriormente, expor a um grupo que deseja também resolvê-lo, a fim de escolher aquela que melhor responde à natureza do desafio, representa um poderoso contexto de aprendizagem partilhada, em que as diferentes hipóteses podem ser questionadas e aprimoradas pelo grupo. Além disso, nesta dinâmica de trocas estabelecida em torno do ato de pensar uma solução para determinada situação, os alunos que apresentam mais dificuldades se beneficiam das competências de seus colegas, que, ao ajudar o grupo, acabam por revisitar e reformular constantemente aquilo que já sabem.

A interação entre aluno e professor também é importante e significativa. Vygotsky (2007) ressalta a importância do inter-relacionamento entre os membros de uma escola, para a ampliação das possibilidades de sucesso na aprendizagem enquanto processo de interação. As ações educativas devem ocorrer num ambiente de interação social, promovendo o intercâmbio entre os diferentes sujeitos escolares. A importância do trabalho em grupo vai além do fato de o aluno trabalhar a sua aprendizagem ao mesmo tempo que seu colega. Passa pelo aumento do índice de responsabilidade e de autoestima dos sujeitos, promovendo, assim, o relacionamento entre alunos e as suas capacidades interpessoais.

Ainda, acredita-se que a capacidade desenvolvida no ato de programar computadores impulsiona a aprendizagem eficiente e o raciocínio lógico. O pensamento lógico parte do indivíduo e da construção de relações existentes entre os objetos, sendo elemento fundamental para que a relação sujeito e objeto tome sentido. Não se trata de um conceito ou uma capacidade que se possa ensinar em um processo direto de 
relação educativa entre professor e aluno. O raciocínio lógico, fundamental ao processo de aprendizagem em qualquer área do conhecimento, desenvolve-se nos momentos em que os indivíduos se deparam com situações em que precisam perceber a demanda por estruturar o pensamento detalhadamente, para resolver determinado problema. Também se desenvolve quando é preciso criar estratégias e testá-las, para aferir a eficiência da solução e, posteriormente, executá-la para identificar sua eficiência. Dessa forma, é possível intuir que o raciocínio lógico não é fruto de atos espontâneos dos indivíduos, mas de atividades que o envolvam, desafiem-no e que possibilitem a criação de uma gama potencialmente infinita de soluções.

Enfim, considerando as características - criatividade, capacidade de resolução de problemas, trabalho em grupo e raciocínio lógico - desenvolvidas em processos de programação de computadores, acredita-se fortemente, e existem diversas pesquisas que apontam para isto, que o ato de programar computadores, por muito tempo associado a profissionais da área de informática, pode constituir uma alternativa poderosa de qualificação da educação, subvertendo a aplicação interdisciplinar dos recursos tecnológicos digitais no ensino.

\section{Ambientes de programação}

A partir da consideração de que Seymour Papert desenvolveu sua prática com a informática educativa baseada na crença de que a criança pode ser vista como um ser aprendiz inato e construtor de suas estruturas de pensamento a partir da exploração do ambiente em que vive, é possível afirmar que Papert procurou um meio que permitisse à criança uma especial realização de descobertas de novos processos de pensar. Com essas ideias, portanto, desenvolveu, com o uso do computador, um meio pelo qual a criança pudesse estabelecer contato com este instrumento versátil, fácil de operar e rico em possibilidades. Com o objetivo de ilustrar esses elementos, serão apresentados alguns softwares específicos de programação, os quais fazem uso da criatividade, são baseados na resolução de problemas e, principalmente, demandam o desenvolvimento de raciocínio lógico: o Logo e o Scratch.

O Logo foi desenvolvido no Massachusetts Institute of Technology (MIT), por Seymour Papert, na década de 1960. Segundo Gonçalves ([2002]), a linguagem de programação Logo apresenta as seguintes características, do ponto de vista computacional: exploração de atividades espaciais, fácil terminologia e capacidade de criar novos termos ou procedimentos. Além disso, uma das características importantes do Logo é a de não possuir objetivo delimitado, isto é, pode ser utilizado 
em ampla gama de atividades. Neste ambiente, o cursor é representado por uma tartaruga, que é dinâmica, possui uma posição e, o que é muito importante, possui uma orientação. A partir desta organização, a "tartaruga" aceita ordens ou comandos que são fornecidos pelas crianças, deixando um rastro na tela por onde passa.

A linguagem utilizada no Logo é uma linguagem procedural e os comandos básicos são termos do cotidiano da criança. A linguagem Logo foi uma das formas de usar o computador que Seymour Papert criou a partir do princípio de que a máquina seria apenas uma máquina e que quem a controlaria, a partir daquele momento, seriam as pessoas. Com a linguagem Logo, o aluno pode indicar o que o computador deve fazer, controlando, assim, a máquina, indicando a ela a tarefa a realizar. Nesse processo, o aluno tem possibilidade de refletir sobre o que faz, buscando possíveis soluções para resolver os problemas, sendo, em sua maioria, problemas matemáticos. A partir desses comandos primitivos, a criança pode criar outros comandos, que são denominados de procedimentos, os quais, uma vez na memória do programa, podem ser executados como os comandos originais.

A abordagem desenvolvida por Vygotsky (2007) encontra respaldo na educação escolarizada, ou seja, permite que se desenvolvam reflexões, procurando o aprimoramento intelectual dos aprendizes, sejam eles crianças, jovens ou adultos. A metodologia que Papert propõe é carregada de significado lúdico, uma vez que proporciona à criança uma situação de brinquedo. O diálogo que se estabelece com a máquina (tartaruga) é, naturalmente, uma atividade de brincadeira, em que a criança aos poucos é levada a aprender as noções básicas do sistema Logo. Ao brincar com a tartaruga, a criança, e até mesmo o adulto, projeta-se nas ações baseadas na própria experiência de deslocamento no espaço, as quais são similares às da tartaruga da tela. Papert, sem dúvida, preocupado com a relação entre o homem, a tecnologia e a natureza da aprendizagem, desenvolveu a linguagem de programação Logo, para ser utilizada por educadores no processo de ensino e aprendizagem.

Embora o Logo seja o precursor dos ambientes de programação em processos educativos, atualmente é pouco utilizado. Entretanto, deu origem a outros programas que tem ganhado destaque no mundo contemporâneo, como é o caso do Scratch, cujo slogan é “imagina, programa, compartilha”. O Scratch é uma nova roupagem para a linguagem de programação Logo. Ele foi divulgado publicamente em maio de 2007 e foi criado como resposta ao problema do crescente distanciamento entre a evolução tecnológica no mundo e a fluência tecnológica dos cidadãos. Foi pensado, igualmente, para promover um contexto construcionista propício ao desenvolvimento da fluência tecnológica nos jovens. Os autores entendem, ainda, 
que sua utilização permitirá avançar na compreensão da eficácia e inovação do uso das tecnologias nas aprendizagens em diferentes domínios e contextos, tornar os jovens criadores e inventores, mais do que meros consumidores de tecnologia, e estimular a aprendizagem cooperativa (EDUSCRATCH, 2012).

O termo "Scratch" provém da técnica de scratching, utilizada pelos disc-jockeys do hip-hop, que giram os discos de vinil com as suas mãos para frente e para trás, de modo a fazer misturas musicais originais. Com o Scratch, é possível fazer algo semelhante, misturando diferentes tipos de clipes de mídia de modos criativos, usando uma programação matemática similar à feita nos programas de computador profissionais, porém de forma muito lúdica, simples e intuitiva. Trata-se de uma aplicação destinada a ser utilizada por crianças a partir dos 8 anos, que foi desenvolvida pela equipe Lifelong Kindergarten, do MIT Media Lab, e coordenada por Mitchel Resnick.

Entre as diferentes habilidades desenvolvidas a partir do Scratch, destacam-se as competências para a resolução de problemas e para a concepção de projetos com raciocínio lógico, a possibilidade de decomposição de problemas complexos em partes mais simples, a identificação e eliminação de erros, o desenvolvimento de ideias, desde a concepção até a concretização do projeto, concentração e perseverança. Os conceitos específicos de programação experimentados são: sequência, iteração em ciclos, instruções condicionais, variáveis, execução paralela, sincronização, interação em tempo real, lógica booleana, números aleatórios, gestão de eventos, desenho de interface do utilizador e estruturas de dados (MARQUES, 2009). Dentre as características básicas da ferramenta Scratch, destacam-se:

a) programação com blocos de construção, denominados building blocks: para escrever programas em Scratch, é necessário encaixar blocos gráficos uns nos outros, formando empilhamentos ordenados chamados de stacks; os blocos são concebidos para poderem se encaixar apenas de forma que façam sentido sintaticamente, não ocorrendo, assim, erros de sintaxe e permitindo realizar várias tarefas diferentes, para produzir o resultado final de acordo com o gosto do usuário; a sequência de instruções pode ser modificada mesmo com o programa em execução, o que facilita a experimentação simples de novas ideias e o cumprimento de instruções paralelas com diferentes conjuntos de blocos;

b) manipulação de mídia: o Scratch permite a construção de programas que controlam e integram gráficos, animação, texto, música e som; amplia as atividades de manipulação de mídia que são populares na cultura atual, 
capturando-as diretamente da webcam ou do microfone do usuário, ou ainda mídias disponíveis em diferentes meios de armazenamento;

c) partilha e colaboração: a página na internet do Scratch fornece inspiração e audiência; os usuários podem experimentar os projetos de outros, reutilizar e adaptar as suas imagens e scripts, além de divulgar os próprios projetos; a meta final é potencializar uma comunidade e uma cultura de compartilhamento em torno do Scratch; é importante salientar que tal dinâmica faz parte do cotidiano digital dos estudantes, acostumados a compartilhar, criar comunidades em torno de assuntos de interesse comum e, principalmente, criar coletivamente.

Se, por um lado, o projeto Scratch é pensado para criar um ambiente de aprendizagem rico e dinâmico, no qual é possível criar histórias interativas, jogos e animações, por outro, possibilita a criação de competências fundamentais à aprendizagem em qualquer situação, como destacado no site dos criadores do programa e identificado em diversas pesquisas realizadas e compartilhadas na internet. Dentre elas, destacam-se: competências de informação; competências de comunicação; competência de raciocínio crítico e pensamento sistêmico; competências de identificação, formulação e resolução de problemas; competência de criatividade e curiosidade intelectual; competências interpessoais e de colaboração; competência de autodirecionamento; competência de responsabilização e adaptabilidade; e competência de responsabilidade social.

Aprendendo a selecionar, criar e gerir múltiplas formas de mídia, incluindo texto, imagens, animação e áudio, as crianças se tornam mais perspicazes e críticas na análise das mídias que observam à sua volta e mais capacitadas a manipular informações em diferentes formatos, processo para o qual o método de ensino formal não prepara, uma vez que é baseado em um número reduzido de formatos de representação de informação. Mesmo em processos educativos on-line, em que a natureza digital potencialmente proporciona o contato com diferentes mídias, o processo de manipulação, interconexão, reorganização e remixagem destas é limitado ou, em muitos casos, inexistente.

O processo de manipulação de informações em diferentes formatos vem acompanhado da possibilidade de desenvolvimento de competências de comunicação, esta entendida como capacidade de transformar seus pensamentos em algo que possa ser visível a outras pessoas, como, por exemplo, histórias interativas, animações ou jogos. Uma comunicação eficaz, no mundo atual, requer mais do que a capacidade de ler e escrever textos. Nessa perspectiva, o Scratch envolve os jovens 
na escolha, na manipulação e na integração de uma grande variedade de mídias, para se expressarem, individualmente, de forma criativa e persuasiva.

Os processos de manipular diferentes formatos de informação para a criação de formas digitais de comunicação e expressão demandam o desenvolvimento de competências que envolvem o raciocínio crítico e o pensamento sistêmico, uma vez que, à medida que aprendem a programar, os jovens adaptam formas de raciocínio crítico e de pensamento sistêmico. Para construir projetos, os alunos necessitam coordenar o tempo e a interação entre múltiplos objetos móveis programáveis. Para tanto, é preciso, necessariamente, identificar uma demanda, formulá-la mentalmente e, finalmente, partir para a implementação da solução. O Scratch instiga a formulação e a resolução de problemas em contextos de concepção e design significativos. Criar um projeto Scratch requer que se pense numa ideia, que depois seja capaz de descobrir como dividir o problema em passos menores e, por fim, concretizá-los, usando os blocos de programação da ferramenta.

Tal solução deverá ser diretamente proporcional à capacidade criativa e à curiosidade intelectual de cada um, processos que se desenvolvem na medida em que se ganha experiência. Programar encoraja o pensamento criativo, pois envolve os jovens na procura de soluções inovadoras para problemas inesperados, preparando-os para encontrar novas saídas, à medida que surgem novos desafios, e não apenas para saber como resolver um problema pré-definido. É importante destacar que a resolução de problemas acaba sendo um processo que leva ao desenvolvimento de competências interpessoais e de colaboração, pois passa pela discussão com pares, pela análise conjunta de possíveis soluções e pela comparação de blocos lógicos de pensamento. Por ser construído com blocos gráficos, o código de programação é mais legível, acessível e compartilhável do que outros programas, permitindo, assim, que os objetos visuais e o código modular facilitem a colaboração, de maneira a possibilitar que projetos sejam trabalhados em grupos, bem como o intercâmbio de objetos e códigos.

Ter uma ideia e descobrir como a programar requer persistência e prática. Quando os jovens trabalham em projetos baseados em ideias que consideram pessoalmente importantes e significativas, estas geram motivação intrínseca para ultrapassar os desafios e as frustrações encontrados no processo de concepção e de resolução de problemas. Na mesma linha, desenvolver um programa que busca a resposta a uma situação específica pressupõe responsabilizar-se por construir uma solução que, caso seja necessário, deve ser adaptada. Criar projetos em Scratch requer que se tenha em mente o público-alvo e o modo como outras pessoas reagirão 
e responderão a eles, uma vez que é fácil modificá-los e revê-los, sendo possível, portanto, alterá-los de acordo com a reação de terceiros.

Por fim, uma vez que o Scratch estabelece uma dinâmica de rede social de desenvolvedores, em que cada um pode compartilhar suas soluções que podem servir de insumo para outras, os alunos podem gerar discussões de assuntos importantes do seu ambiente de aprendizagem mais próximo como a turma ou a escola, bem como da mais vasta comunidade internacional do Scratch.

No âmbito dessas discussões, destacamos brevemente dois projetos em desenvolvimento no município de Passo Fundo, nos quais foram exploradas questões sumariamente apresentadas neste texto. O primeiro, denominado Escola de Hackers, é desenvolvido pela Prefeitura Municipal de Passo Fundo com apoio da UPF, da Faculdade Meridional e do Instituto Federal Sul Rio-Grandense, com o objetivo de oportunizar um espaço para desenvolvimento de competências na área de programação de computadores e de raciocínio lógico matemático para estudantes do ensino fundamental da rede pública municipal de Passo Fundo. Destinado a alunos do $6^{\circ}$ ao $9^{\circ}$ ano e a professores de 36 escolas, em 2014 , foi realizado o projeto piloto com 250 alunos de 20 escolas do município. Embora não seja o foco deste texto, destaca-se que, ao final do projeto, foi possível identificar indícios dos elementos teóricos e das reflexões feitas acerca do potencial da programação de computadores no desenvolvimento de habilidades e competências cognitivas entre os participantes.

O segundo projeto é o Mutirão pela Inclusão Digital, vinculado ao curso de Ciência da Computação da UPF, que propõe processos de formação a grupos em situação de vulnerabilidade e risco social, assumindo papel ativo na sociedade em rede, por meio de ações realizadas na instituição, em uma perspectiva de comunicação e exercício da cidadania. $O$ projeto teve seu início com as oficinas de Informática e Cidadania, que acontecem no Laboratório Central de Informática da UPF. Em 2014, desenvolveram-se atividades com duas turmas de educação infantil, desafiando-as a aprender habilidades e competências necessárias à programação de computadores, como nova forma de estruturar o pensamento e produzir conhecimento. Essa iniciativa é pioneira e pretende trazer uma nova proposta para a metodologia utilizada na educação infantil da região. Para tanto, foram realizadas oficinas de programação de computadores para crianças de 5 e 6 anos de uma escola de educação infantil do município, utilizando o software Scratch Jr. Inspirado no Scratch, esta solução foi lançada em 2014, somente para iPad, e possibilita a construção de histórias interativas e jogos. 


\section{Alguns elementos finais}

A proposta deste texto é trazer uma reflexão acerca do potencial da programação de computadores no desenvolvimento de competências que possam trazer desdobramentos positivos para os processos educativos formais. Assumir a programação de computadores como prática nos laboratórios de informática abala significativamente o que se tem desenvolvido até então na área, seja do ponto de vista metodológico, da concepção da informática como meio de desenvolvimento de projetos interdisciplinares, do processo de formação docente e, em última instância, do papel dos computadores na educação.

É claro que não se preconiza o fim da informática educativa tal como tem sido, em muitas das vezes, realizada nas escolas e universidades. Entretanto, deseja-se criar situações diversas para uma discussão mais aprofundada e para a realização de experiências práticas que possam de fato explorar o potencial da programação de computadores no desenvolvimento cognitivo do aluno e como alternativa compatível com o mundo contemporâneo, baseado na abundância de possibilidades, em que a competência de articular informações existentes é mais importante do que memorizá-las.

Sugere-se, para estudos futuros, que se pesquisem os resultados da aprendizagem ativa de muitas turmas com o emprego do Scratch, bem como as dificuldades e as possíveis novas formas de trabalho colaborativo nas escolas, com o incentivo e o desenvolvimento de novos programadores nos estudantes.

\section{Notas}

1 O relatório completo do Pisa 2012 está disponível em: <http://goo.gl/6bqYUz>.

2 Um dos primeiros textos que chamavam atenção para a possibilidade de utilização educacional dos computadores foi escrito por Seymour Papert e Cynthia Solomon em 1971: Twenty things to do with a computer. Disponível em: <http://goo.gl/aWZoMn>. Acesso em: 24 jun. 2018.

\section{Referências}

EDUSCRATCH. Programação robótica no ensino básico. 2012. Disponível em: <http://eduscratch.dge.mec.pt/>. Acesso em: 20 ago. 2018.

GONÇALVES, Daniela. Linguagem Logo. [2002]. Disponível em: <http://aprendercom.org/escola21/file/download/8395>. Acesso em: 23 set. 2018.

LEMOS, André. Cibercultura: tecnologia e vida social na cultura contemporânea. Porto Alegre: Sulina, 2002. 
MARQUES, M. T. P. M. Recuperar o engenho a partir da necessidade, com recurso às tecnologias educativas: contributo do ambiente gráfico de programação Scratch em contexto formal de aprendizagem. Dissertação (Mestrado em Ciências da Educação) - Universidade de Lisboa, 2009. Disponível em: <http://repositorio.ul.pt/handle/10451/847>. Acesso em: 22 set. 2018.

ORGANISATION FOR ECONOMIC CO-OPERATION AND DEVELOPMENT. Índice para uma vida melhor: Ranking Educação. 2014. Disponível em: <http://goo.gl/a8n8tD>. Acesso em: 25 jun. 2018.

PAPERT, Seymour. A máquina das crianças: repensando a escola na era da informática. Porto Alegre: Artmed, 2007.

PÓLYA, G. Como resolver problemas: um aspecto novo do método matemático Lisboa: Gradiva, 2003.

PONTE, J. P. et al. Programa de matemática do ensino básico. Lisboa: DGIDC, 2007.

VEEN, W.; VRAKKING, B. Homo zappiens: educando na era digital. Trad. Vinicius Figueira. Porto Alegre: Artmed, 2009.

VYGOTSKY, Lev. A formação social da mente. 2. ed. São Paulo: Martins, 2007. 